Please do not remove this page

RMIT

UNIVERSITY

\title{
Development of risk assessment tool using damaging energy and argumentation theory for evaluating construction occupational safety and health risks
}

Abas, Nor Haslinda; Blismas, Nick; Lingard, Helen

https://researchrepository.rmit.edu.au/esploro/outputs/9922035780901341/filesAndLinks?institution=61RMIT_INST\&index=null

Abas, N. H., Blismas, N., \& Lingard, H. (2021). Development of risk assessment tool using damaging energy and argumentation theory for evaluating construction occupational safety and health risks. Engineering, Construction and Architectural Management, 28(10), 2967-2993.

https://researchrepository.rmit.edu.au/discovery/fulldisplay/alma9922035780901341/61RMIT_INST:Resea rchRepository

Document Version: Accepted Manuscript

Repository homepage: https://researchrepository.rmit.edu.au

CC BY-NC V4.0

(C) Emerald Publishing Limited

Downloaded On 2023/04/27 01:18:16 +1000 


\title{
Development of Risk Assessment Tool Using Damaging Energy and Argumentation Theory for Evaluating Construction Occupational Safety and Health Risks
}

\begin{abstract}
Purpose - The purpose of this paper is to describe the development of a risk assessment model to assess the occupational safety and health $(\mathrm{OSH})$ risks presented by different construction approaches,namely traditional and Industrialised Building System (IBS). The development process applies the concept of argumentation theory, which helps construction designers integrate the management of OSH risk into the design proces. In addition, an energy damage model is used as an underpinning framework for developing the model.
\end{abstract}

Design/methodology/approach - Development of the model was achieved through two phases. Phase I involved collection of data on the activities involved in the construction process and their associated OSH risks, derived from five different case studies, field observation and interviews. Knowledge on design aspects that have the potential to impact on OSH was obtained from document analysis. Using the knowledge obtained in Phase I, a model was developed in the form of argument trees (Phase II), which represent a reasoning template with regard to options available to designers when they make judgements about aspects of their designs. Inferences from these aspects eventually determined the magnitude of the damaging energies for every activity involved. Finally, the model was validated by panels of experts, and revisions and amendments were made to the model accordingly.

Findings - The risk assessment model development revealed that the concept of argumentation theory and energy damage model is suitable to represent design safety risk knowledge and effectively address the designer's role in making decisions in their designs and further illuminate the level of OSH risk their designs pose.

Practical implications -

The developed model provides best-practice reasoning support for construction designers, which help them to understand the impact of their designs decisions on worker's safety and health, and thereby assist them to further mitigate the risk to an acceptable level.

Originality - This study departs from existing tool in that the model was developed based upon the combination of argumentation theory and energy damage model. The significance of the model is discussed

Keywords Occupational safety and health, Construction industry, Industrialised Building System, Damaging energy, Argumentation theory, Knowledge processes

\section{Introduction}

The Malaysian construction industry plays a significant role in the development and growth of the country's domestic economy, generating further demands for construction activities (Abdullah and Wern, 2011; Hamid et al., 2008; Hosseinian and Torghabeh, 2012). However, the industry has earned the reputation of being a highly hazardous industry due to its high rates of accidents and fatalities (Ayob et al., 2018; Shamsuddin et al., 2015). There is therefore an urgent need to improve health and safety performance of Malaysia's construction industry.

Accident statistics for the Malaysian construction industry, as reported in the Social Security Organization (SOCSO) Annual Report, are too high (Foo, 2005; SOCSO, 2000, 2009, 2019). The most recent figures produced by the Department of Occupational Safety and Health (DOSH) reveal that seventy-two (72) out of two-hundred and fourteen (214) fatality cases were attributed to the construction industry in 2019 (DOSH, 2019). These reports provide clear evidence that the industry is one of the critical sectors in need of a significant and rapid overhaul to its current site safety practices (Shah et al., 2016). This paper suggests that understanding the hazards within different construction processes, such as IBS, will provide critical new information that can help improve construction health and safety. 
The Government of Malaysia is supporting an initiative to cultivate and strengthen positive safety cultures in working places. This is shown through the formulation of the Construction Industry Transformation Program (CITP) 2016-2020, which was introduced with the aim to transform the construction industry to be highly productive, environmentally sustainable, with globally competitive players (CIDB, 2016.). Moreover, it provides a strategic vision and direction for work safety and health in Malaysia. One of the key strategies which related to this research is through 'preventive workplace culture' that can be achieved through designing and developing the safe environments, systems and products, which is known as Prevention through Design (PtD). In this concept, designers (such as architects and engineers) assess the identified risks their designs create to the workers on construction sites, and eliminate or modify the design to eliminate hazards and/or minimize the impact of the risks. The importance of incorporating safety during the design phase is emphasized by Szymberski (1997), Cooke (1997) and_Gambatese et al. (2008). The evidence of the effectiveness of this strategy is confirmed by several authors, such as Jeffrey \& Douglas (1994), Gibb et al. (2004), Behm (2006), Gambatese et al. (2008).

Furthermore, the Guidelines on Occupational Safety and Health in Construction Industry (Management) (OSHCI(M) 2017 has been introduced by the Ministry of Human Resources, through the Department of Occupational Safety and Health (DOSH) (DOSH, 2017a). This guideline aims to integrate the PtD principles as part of initiatives to address the capability of construction stakeholders in improving OSH performance. OSHCI(M) was developed based on the Construction Design and Management (CDM) Regulation 2015 in the UK. However, the PtD requirements in Malaysia are still at voluntary basis (DOSH, 2017b), unlike other countries such as UK, Australia and Singapore (Che Ibrahim et al., 2019). As such, it is doubtful that Malaysian construction designers adequately understand how to identify, assess and control OSH risks in their designs. This is proven in Che Ibrahim et al. (2019) who found that the PtD knowledge among construction designers still needs to be improved, where most respondents answered less familiar with the types of hazards controls.

Therefore, it is vital to have a structure that can assist Malaysian construction designers to better integrate OSH risk management into the design process. Risk management can be a mechanism in applying the concept of designing for construction safety. However, there is lack of risk assessment methodology for mitigating the incidents and accidents by guiding the construction process in Malaysia. The most well-recognized method would be Hazard Identification, Risk Assessment and Risk Control (HIRARC), developed by DOSH. However, its assessment method is generally quantitative and relies heavily on OSH expert opinions, which does not encourage use by other stakeholders i.e designers and contractors. Apart from HIRARC, the Construction Industry Development Board (CIDB) has developed a quantitative safety and health assessment named 'Safety and Health Assessment System in Construction (SHASSIC)', which has three components of data gathering i.e. document check, workplace inspection and employee interviews (Misnan, 2013). This method lacks any predictive ability in that it can only measure the present safety performance of construction in Malaysia (Abas et al., 2016).

In order to address these deficiencies, this study developed a risk assessment model that can compare the risk level inherent in different construction approaches throughout the construction process. This is useful to inform decisions that are made by designers that can impact the occupational safety and health of people involved in the construction of a building or structure. The novelty of the developed model is that it measures the extent of the impact of IBS upon safety and health in construction, which is in line with the government's desires of widespread adoption of Industrialized Building Systems (IBS) in construction projects. An IBS approach is commonly deemed to be safer than conventional construction because it changes the nature of the construction process, and requires fewer workers onsite. This paper presents the development of the model, which eventually could determine the relative safety and health performance of the different construction processes (such as IBS and traditional approaches). This article expands on an earlier working papers by Abas et al. $(2011,2016)$, in which the main background and methodology of this research is described.

The risk assessment model developed in this study applied an argumentation framework (Cooke et al., 2008) with an energy damage model (Viner, 1996) as an underpinning framework for developing the model. The concept of argumentation was chosen since it provides the framework for modelling best practice reasoning that can be made by product and process designers, in such a way 
as to assess the extent to which their design decisions mitigate the OHS risk in construction. Meanwhile, the concept of the energy damage model was chosen due to: i) its unique characteristic which views hazards as a source of potentially damaging energy and risk; and ii), its ability to provide strategies to prevent injury which does not depend on human or behaviour changes. The combination of these concepts thereby offers a more rigorous relative comparison of OHS risks between IBS and traditional approaches.

The development of this risk assessment model is important due to some major flaws identified in other methods for comparing different construction processes/approaches. The flaws identified in Gangolells et al. (2010) and McKay (2010) include: i) providing only static assessments that simply list hazards of specific processes; ii) presenting risks as snapshots, rather than profiling risks over time; and iii) failing to deal with dynamic work environments as workplace risks are emergent and change over time. This study sought to deal with these limitations and also sought to determine the relative safety of different construction processes.

\subsection{The relative safety of IBS}

Of the many initiatives that could be implemented to improve OSH performance, offsite construction (commonly termed IBS in Malaysia) has been suggested as a replacement to traditional construction methods (CIDB, 2007). The Malaysian government is actively promoting the adoption of IBS and encouraging a paradigm shift in the construction process, from a traditional to an industrialized approach. This is demonstrated by the promulgation of the Construction Industry Master Plan (CIMP) 2006-2015 (CIDB, 2007), which specifically mentions IBS and its implementation through IBS Roadmaps.

The nature of activities in IBS differs from that of traditional processes. IBS is an industrialized process in which components of a building are conceived, planned, and fabricated, and then transported to and erected on site (Junid, 1986). Claims have been made that IBS, or more specifically offsite construction, can reduce site accidents (Abas et al., 2018; Mat Nasir et al., 2012; Gibb, 1999; Toole and Gambatese, 2008; Gangolells et al., 2010; Mckay, 2010). However, the extent of this impact on safety and health in construction is still unclear, as there are no current systems to comparatively assess OSH risks in different construction processes. McKay (2010) has identified the OSH risks of both onsite and the offsite processes, but presents a static assessment that lists hazards of specific processes, rather than comparing the extent of the risks of the various processes. There is therefore a need for a robust dynamic method for comparing different construction processes, such as IBS and traditional approaches, to determine the relative safety and health performance of these processes. Further, the context of the Malaysian construction industry needs to be superimposed on this methodology as current work is centred on developed industries such as the UK/Europe, US and Australia.

\subsection{Proposed risk assessment model}

An 'argumentation theory model' (Toulmin, 1958; as cited in Yearwood and Stranieri, 2006) building on the work of Cooke et al. (2008) (named ToolSHED) is proposed as a method to integrate the management of occupational health and safety risk into the design process. ToolSHED is an Australian decision support tool for design OSH in the construction industry, which provides a simple step-by-step approach to the assessment of the risk of falling from heights presented by features of a building's design. ToolSHED was developed from structured knowledge in the context of uncertainty and discretionary decision making, involving expert reasoning regarding design impacts on OSH risk represented by 'argument trees' (Cooke et al., 2008). According to Cook et al. (2008, p.341), 'the risk assessment [in ToolSHED prototype] prompts designers to enter information about relevant design features that experts agree could impact upon the risk of falling from height. The data entered are then used to infer a risk rating based upon a reasoning model agreed by a panel of experts. A risk report is generated as a system output. This advises the designer as to the level of risk of falling from height (Extreme, High, Medium or Low) and an explanation of the design factors contributing to this inferred level of risk.' Based on the report, a designer can choose whether to accept the level of risk and proceed, or modify the design features (that has potential to produce high risk) in order to reduce the risk to an acceptable level. 
Building on the concept of argumentation theory and using the energy damage model (Viner, 1991) as an underpinning framework, this study seeks to develop a process-centric risk assessment model that consists of a series of argument trees for best practice reasoning that can be used by designers or decision makers when examining the OSH risks posed in different construction processes. The argument trees consist of knowledge which were developed by focusing on the processes involved in building a product using various construction processes. The model provides consideration of product and process design concurrently, thus contributing to the body of knowledge.

\subsubsection{Argumentation theory}

Argumentation theory can be used to represent the modelled knowledge as an alternative to rules. In this theory, a series of 'argument trees' is represented from the captured design OSH knowledge as an alternative to Knowledge-Based Systems (KBSs), which use knowledge to support human decision making in a complex situation. This is due to the limitations of KBSs which use 'IFTHEN' rules in problem solving processes.

\subsubsection{Knowledge-Based Systems and its Limitation}

Cooke et al (2008, p. 338) argue that "the effectiveness of rule-based KBSs for directing compliance with OSH legislations is doubtful due to the performance-based nature of the OSH legislation in many countries". According to Cooke et al. (2008), many countries which follow the UK model have reformed the OSH legislation from detailed and prescriptive requirements to performance-based requirement since the UK legislation shift in mid-1970s. These countries have addressed 'general duties' for employers, employees, suppliers of plant and materials and others. The 'general duties' provisions incorporated into performance-based OSH legislation in many countries are not absolute and are limited by words such as 'so far as is practicable' or 'reasonably practicable'. The term open-texture refers to a situation in which problems cannot be precisely defined and rules are not exhaustive, requiring human interpretation, judgement and discretionary decision-making.

Neither can the vagueness characteristics of real world problems be adequately solved using simple 'IF-THEN' rules (Ghosh et al., 2017). Lingard et al. (2006) argue that the rule-based KBSs are problematic due to their tedious and difficult task when dealing with the real world. In the real world, where the rule sets to solve problems are large and might exceed 10,000, Lenat (1983, as cited in Cooke et al., 2008) observes that the sheer number of rules required to reflect real world problemsolving would require considerable amount of time to capture and model in a KBS. Lenat refers to this as creating a knowledge acquisition bottleneck. Furthermore, available inference engines that are used to control the selection and use of data in web-based KBSs and apply reasoning necessary to solve problems are also unable to cope with such large rule-sets, preventing real-time resolution of problems (Cooke et al., 2008). Therefore, "it is difficult for researchers to exactly mimic and generate human-like reasoning and thought process in a model of natural intelligence (Akerkar and Sajja, 2010, pg. 24)". Once implemented, KBS models are often slow and unable to access or manage large volumes of information; further, they can be difficult to maintain (Arkerkar and Sajja, 2010). In addition, a belief-rule based methodology (known as RIMER) has been introduced to enhance the limitation of IF-THEN rules (Liu et al., 2013; Calzada et al., 2013). However, there are still challenges on how this advanced rule-based system can be applied into big data analytics, especially how to combine and incorporate the domain expert knowledge into the big data analysis for decision making purpose (Liu, 2016).

The open-textured nature of performance-based OSH legislation suggests that expert reasoning cannot be easily or comprehensively modelled by rules due to the large number of interrelated and heterogeneous factors that revolve around the requirements. In executing their duties, duty holders, therefore need to balance OSH risk against cost and technical possibility, and decisionmakers need to base decisions on an assessment of the magnitude of OSH risks and the effectiveness (and cost) of available methods of controlling risks (Cooke et al., 2008). Therefore, Cooke et al. (2008) suggest the use of argument trees for modelling expert reasoning as better suited to solving problems in such situations.

\subsubsection{Argument trees}


In this study, a series of argument trees will be used to evaluate OSH risk from modelled expert reasoning in a way to determine the relative OSH risks of IBS versus traditional construction processes. Reasoning is the process of seeking a rational or reasonable standpoint or decision (Evans et al., 1993). Human reasoning in relation to open-textured problems can be represented in the form of argument trees. Using argument trees as an approach to represent the knowledge of design OSH is useful because design OSH is subjective and interconnected to other issues that require concurrent considerations. The idea of representing knowledge from argumentation was initiated by Toulmin (1958; as cited in Cooke et al., 2008), but, however, he loosely specifies how arguments relate to other arguments and provides no guidance as to how to evaluate the best argument (Yearwood and Stranieri, 2006).

Therefore, Yearwood and Stranieri (2006) use 'argument trees' graphically to clarify the hierarchical ordering of factors pertinent in decision making processes. In argument trees, all arguments consist of one conclusion represented by a single 'root' node that are proven or supported by 'child' and 'parent' nodes. The nodes are connected by lines that represent the relevant relations in an argument structure. The values on 'children' nodes will conclude the linguistic variable value on the 'parent' node using the pre-determined inference procedures, which ultimately give the value of the 'root' node. The inference process depicts a template for reasoning in complex situations (Cooke et al., 2006).

\subsubsection{Energy damage model}

In developing a model that represents the reasoning for decisions around the construction processes, the same method of modelling as the expert reasoning system in ToolSHED, in the form of a series 'argument trees', will be used. However, the argument trees developed in this study will be underpinned by an energy damage model in construction processes to assess OSH risks in the design. The energy damage model, created by Viner (1991), suggests the identification and control of potentially harmful energy to eliminate or reduce the latent conditions of the unsafe person while operating in an unsafe place. This is underpinned by, 'when an unwanted and harmful energy source is transferred unexpectedly (in type, time, speed or force) or to an unwilling or unwitting person, the problem may arise even though the energy itself is not dangerous'. As the high amount of damaging energies to penetrate the barrier shield could determine the level of injury to the recipient, reducing the amount of these energies will become increasingly important.

The novelty of the energy damage model is it emphasis on technological control in order to eliminate the potential damaging energies or reduce the amount of injury to the recipient, rather than depending on worker behaviour. The technological controls can be engineering or design controls, which designers can use in order to prevent accident or injury. According to Viner's Energy Damage Model, in order to cause damage, energy has to penetrate the barrier and transfer to the recipient. The extent of damage depends on the amount of energy that exceeds the energy threshold of the recipient. The types of damaging energies (hazards) include gravitational; noise and vibration; chemical; electrical; mechanical/kinetic; thermal; radiation; microbiological; biomechanical; and psychosocial (Safetyline Institute, 2005).

\section{Development Process of the Model}

Integrating the energy damage model with argument trees provides a powerful tool for assessing construction process risk. The approach used to develop the model is depicted in Figure 2. It consists of two stages, initiated with knowledge acquisition, followed by knowledge processing. 


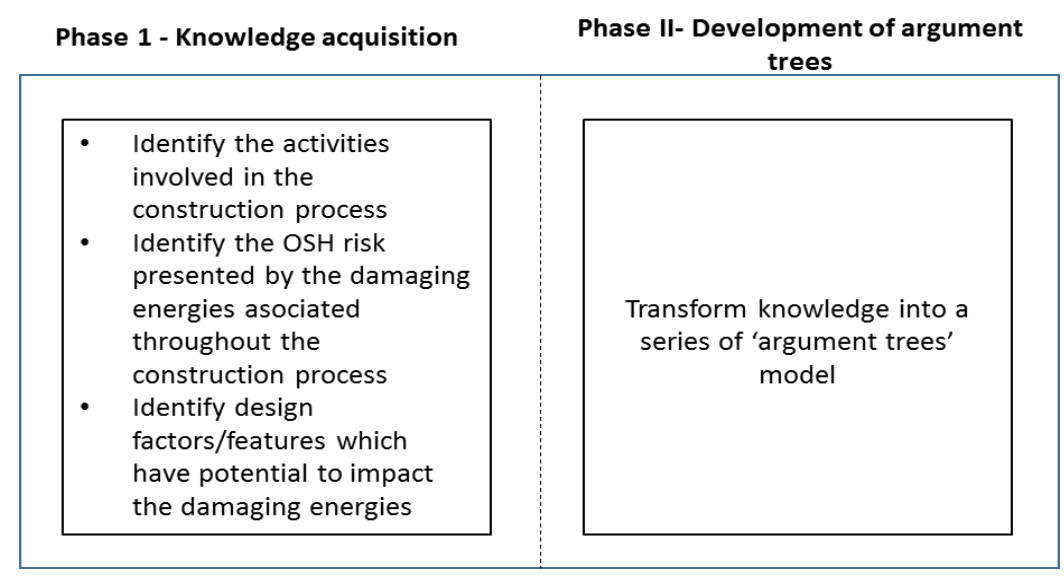

Figure 2: Model development process

\subsection{Phase I - Knowledge acquisition}

Knowledge acquisition involves collecting the data that will underpin the model, which includes the construction process, the associated risks and the design aspects which have potential to impact construction risks. Data was collected by the authors on on-going construction projects, which used the selected construction approaches in order to observe the process involved and to identify the associated OSH risks.

Five case studies were chosen for this study, in which four of them were in IBS/offsite and one in traditional construction (as detailed in Table 1). These numbers, which represent different construction methods were a convenient sample and enough to cover a spectrum of building envelope and structure types in residential building. The 4:1 ratio of construction methods (IBS/offsite : traditional construction) was chosen due to the several different IBS/offsite construction approaches involved. Whereas for traditional construction, one case was chosen because the method (in situ conrete and masonry) is the most common traditional approach used for building construction. The Australian case was chosen to enable thorough comparison of risk evaluation for different construction approaches. The Australian Panelised System can be also categorized as an IBS in terms of its construction method. The approach differs from IBS wall panel systems typical of Malaysia in that it utilizes light-weight material. This could potentially yield different risk ratings for the various IBS wall panel systems during the construction process.

The detailed studies involved talking to the managerial staff, operatives and supervisors, and observing and documenting operations. Document analysis techniques were also used to obtain the information regarding 'safe design' aspects generally associated with construction processes. This data source was extracted from OSH guidance material, industrial standards and odes. These were used to provide the design related information during the development of the argument trees.

Table 1: Details of selected research case examples

\begin{tabular}{|l|l|l|l|}
\hline \multicolumn{1}{|c|}{$\begin{array}{c}\text { Description of research } \\
\text { participants }\end{array}$} & \multicolumn{1}{|c|}{ Project description } & \multicolumn{1}{|c|}{$\begin{array}{c}\text { Methods of data } \\
\text { collection }\end{array}$} & \multicolumn{1}{|c|}{ Location/Source } \\
\hline $\begin{array}{l}\text { Construction approach: } \\
\text { In situ concrete and } \\
\text { masonry method }\end{array}$ & $\begin{array}{l}\text { Construction of 3-storey } \\
\text { semi-detached house using } \\
\text { conventional method }\end{array}$ & $\begin{array}{l}\text { • Field observation } \\
\text { - Interview 3 project } \\
\text { personnel }\end{array}$ & Kuala Lumpur, Malaysia \\
\hline $\begin{array}{l}\text { Construction approach: } \\
\text { Column-wall panel system } \\
\text { (IBS) }\end{array}$ & $\begin{array}{l}\text { Construction of 4-storey } \\
\text { hostel using precast } \\
\text { column-wall panel system. } \\
\text { The precast panel acted as } \\
\text { a load bearing wall }\end{array}$ & $\begin{array}{l}\text { - Field observation at the } \\
\text { factory and construction } \\
\text { site } \\
\text { - Interview 3 project } \\
\text { personnel }\end{array}$ & $\begin{array}{l}\text { Precast concrete } \\
\text { manufacturer and } \\
\text { contractor } \\
\text { Selangor, Malaysia } \\
\text { (precast factory and } \\
\text { batching plant); } \\
\text { and } \\
\text { Melaka, Malaysia } \\
\text { (construction site) }\end{array}$ \\
\hline
\end{tabular}




\begin{tabular}{|c|c|c|c|}
\hline $\begin{array}{l}\text { Construction approach: } \\
\text { Precast frame system (IBS) }\end{array}$ & $\begin{array}{l}\text { Construction of 4-storey } \\
\text { hostel using precast frame } \\
\text { system. In this system, the } \\
\text { beam and column are } \\
\text { precast, whereas the wall is } \\
\text { constructed using concrete } \\
\text { masonry units (CMU) }\end{array}$ & $\begin{array}{l}\text { - Field observation at the } \\
\text { fabrication yard and } \\
\text { construction site } \\
\text { - Interview } 2 \text { project } \\
\text { personnel }\end{array}$ & $\begin{array}{l}\text { Precast concrete } \\
\text { manufacturer and } \\
\text { contractor } \\
\text { Selangor, Malaysia } \\
\text { (factory); } \\
\text { and } \\
\text { Melaka, Malaysia } \\
\text { (construction site) } \\
\end{array}$ \\
\hline $\begin{array}{l}\text { Construction approach: } \\
\text { Blockwork system (IBS) }\end{array}$ & $\begin{array}{l}\text { Construction of 2-storey } \\
\text { academic block using } \\
\text { blockwork system. This } \\
\text { system uses interlocking } \\
\text { CMU to build the structure } \\
\text { and envelope of the } \\
\text { building where the CMU } \\
\text { itself acts as a load bearing } \\
\text { structure }\end{array}$ & $\begin{array}{l}\text { - Field observation at the } \\
\text { factory and construction } \\
\text { site } \\
\text { - Interview } 3 \text { project } \\
\text { personnel }\end{array}$ & $\begin{array}{l}\text { Blockwork system } \\
\text { manufacturer and } \\
\text { contractor } \\
\text { Selangor, Malaysia } \\
\text { (factory); } \\
\text { and } \\
\text { Johor, Malaysia } \\
\text { (construction site) }\end{array}$ \\
\hline $\begin{array}{l}\text { Construction approach: } \\
\text { Panelized system (offsite) }\end{array}$ & $\begin{array}{l}\text { Construction of single- } \\
\text { storey detached house } \\
\text { using panelized system }\end{array}$ & $\begin{array}{l}\text { - Field observation at the } \\
\text { factory } \\
\text { - Document analysis }\end{array}$ & $\begin{array}{l}\text { Volume panelized home- } \\
\text { builder, Queensland, } \\
\text { Australia }\end{array}$ \\
\hline
\end{tabular}

\subsection{Phase II - Development of argument trees}

\subsubsection{Knowledge processing}

After obtaining the required data from the case study method and secondary sources, the knowledge was arranged in a tabular form for simplicity when comparing the process involved in selected construction approaches. Within this phase, the risks/hazards associated with the activity were categorized into several damaging energies. Table 2 shows one example of the table containing the damaging energies involved in the activity - delivery of IBS column-wall panels to site.

Table 2: Example of the damaging energies for 'delivery' works using an IBS column-wall panel system.

\begin{tabular}{|l|l|l|}
\hline Activities & Damaging energies & Risks/Hazards \\
\hline Prepare for transportation & - & - \\
\hline \multirow{2}{*}{$\begin{array}{l}\text { Loading column-wall panel onto } \\
\text { truck }\end{array}$} & Kinetic energy & Craneage risk \\
\cline { 2 - 3 } & Gravitational energy & Craneage risk \\
\hline \multirow{2}{*}{$\begin{array}{l}\text { Transport and deliver column- } \\
\text { wall panel to site }\end{array}$} & Kinetic energy & Road traffic risks \\
\cline { 2 - 3 } $\begin{array}{l}\text { Off-loading column-wall panel at } \\
\text { site }\end{array}$ & Gravitational energy & Stability of component \\
\cline { 2 - 3 } $\begin{array}{l}\text { Storage of column-wall panel at } \\
\text { site }\end{array}$ & Gravitational energy & Craneage risk \\
\hline
\end{tabular}

It should be noted that 'body muscle energy', 'radiation energy', 'thermal energy', 'microbiological energy' and 'psychosocial energy' were excluded from the modelling process. The main reason to exclude these damaging energies in this study was because their injuries are not a major contributing factor to work-related fatalities, if compared to other damaging energies like gravitational, kinetic and electrical. This is highlighted by Lingard and Wakefield (2019), who identified the similarities of fatalities in the construction industries in the UK, Australia and US, which are fall from height, being trapped by something collapsing/overturning, being struck by a moving or falling object, being struck by a moving vehicle, contact with electricity and contact with moving machinery. A similar scenario appears in Malaysia too, as postulated by several researchers such as Ayob et al. (2018), Rafindadi et al. (2020) and Abas et al. (2020). One may notice that the types of fatality causes above are related to gravitational, kinetic and electrical damaging energies. In addition, another reason for body muscle energy was excluded because the evaluation of ergonomic assessment requires expertise background in conducting ergonomic audits. In addition, its argument tree development is complicated as it also involves problems related to physiological variables, biomechanics and work postures aside from manual handling.

Next, the information related to design aspects which have potential to impact upon the damaging energies gathered in secondary sources (collected in Phase I) were used to develop an 
initial representation of the relevant knowledge in argument trees. This information was used to form the knowledge represented within the argument tree.

\subsubsection{Formulating design aspects for reasoning purposes in the argument trees}

The data obtained regarding the factors that have an impact on damaging energies were analysed and translated into design options that could be made by designers according to the types of damaging energies involved. The boundary was set for the assessment, in which irrelevant factors that are beyond designer's control such as factors relating to training, expertise and brand of the equipment, were not considered. For demonstration, the 'delivery' stage of the components or materials from a manufacturing facility to the site is used as an example. Hence, the presentation of the argument tree model will describe the activity within this stage only.

\section{Delivery phase - example}

Data related to design considerations that should be acknowledged during delivery of components or materials are described in Table 3. These data are applicable for comparing both building envelope and structures using traditional approaches and IBS.

Table 3: Factors considered for developing argument trees for delivery of components to site.

\begin{tabular}{|c|c|c|}
\hline $\begin{array}{c}\text { Damaging } \\
\text { energies }\end{array}$ & Activities & Design features to be considered \\
\hline \multirow[t]{3}{*}{$\begin{array}{l}\text { Gravitational } \\
\text { energy }\end{array}$} & $\begin{array}{l}\text { Loading the materials onto } \\
\text { truck; off-loading materials } \\
\text { at site }\end{array}$ & $\begin{array}{l}\text { The capacity of the lifting plant to support the weight } \\
\text { of element; the vertical distance for the element to be } \\
\text { lifted up; the adequacy of lifting equipment in terms of } \\
\text { the method of lifting, the adequacy of lifting points, } \\
\text { the condition of equipment/lifting plant; exclusion } \\
\text { zone for non-involved workers; and surrounding } \\
\text { factors during the process which include ground } \\
\text { condition, site slopes for truck landing, velocity of } \\
\text { element and wind speed }\end{array}$ \\
\hline & $\begin{array}{l}\text { Delivery (transportation) of } \\
\text { materials to site }\end{array}$ & $\begin{array}{l}\text { The adequacy of restraint equipment and anchor } \\
\text { points to hold the loads; the condition of vehicle } \\
\text { (truck) }\end{array}$ \\
\hline & Stacking of materials at site & $\begin{array}{l}\text { The way materials are stacked; the adequacy of } \\
\text { supports for stacking materials; ground condition } \\
\text { around the stacking area }\end{array}$ \\
\hline
\end{tabular}

\subsubsection{Translation into argument trees}

Once relevant design aspects were identified, the information is then translated into a series of argument trees. In developing the trees, data captured were broken down into several sections according to the type of damaging energies and construction stages. The following paragraphs describe the main considerations involved in translating the gathered information (knowledge), using it to form the structure of the argument tree. For demonstration purposes, the development of the argument tree for gravitational energy during the 'delivery' stage is shown, based on the information gathered through document analysis, as depicted in Table 3 above.

\section{(i) Structure of the argument tree}

The first step involved structuring the knowledge of the argument tree according to the design factors identified. It is to be noted that the argument trees were divided into different types of damaging energy categories and the construction stage involved (e.g., manufacturing, delivery, component installation and in situ works). For example, the first design factor in Table 3, which is 'the capacity of lifting plant to support the weight of element', is inserted into a box (see Figure 3). This box and other similar boxes are called 'nodes'. At the end of the tree, a box containing a statement of the final OSH risk rating of the damaging energy is placed. This box is called 'root node'. The argument tree structure 
usually consists of several nodes representing design factors which have the potential to impact upon the damaging energy. The value of these nodes will be used to infer the value of the root node, which will give the final OSH risk rating: low, medium, high or extreme. In between these two nodes, a small box is placed to represent the inference procedure.

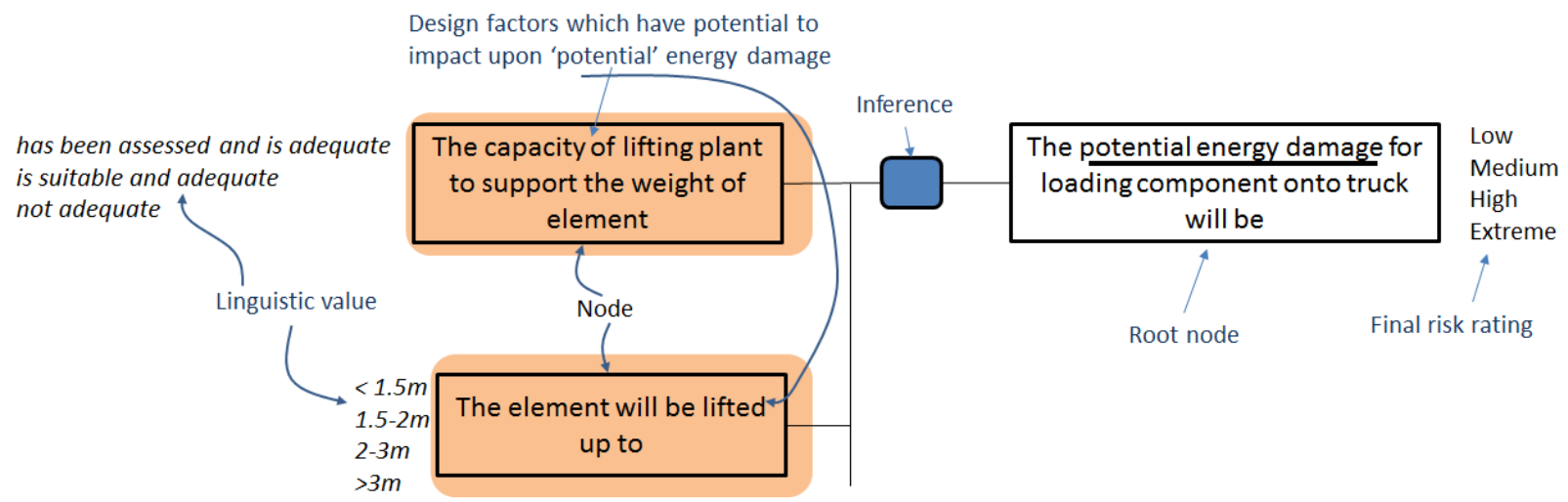

Figure 3: Example of the argument tree structure

ii)

\section{Child nodes and parent node}

Each node containing design factors/aspects may consist of a single node or even be inferred by other predecessor factors/aspects. The reason for this is because some knowledge may be dependent on other factors. For example, the value of the root node (see Figure 4) is evaluated by the values of 'node 1' and 'node 2'. Meanwhile, the value of 'node 1' is dependent upon the values given by 'node a' and 'node b'. Therefore, 'node 1' is called the 'parent node', whereas 'node a' and 'node b' are called 'child nodes'. As can be seen in the figure, 'node 2' is independent.

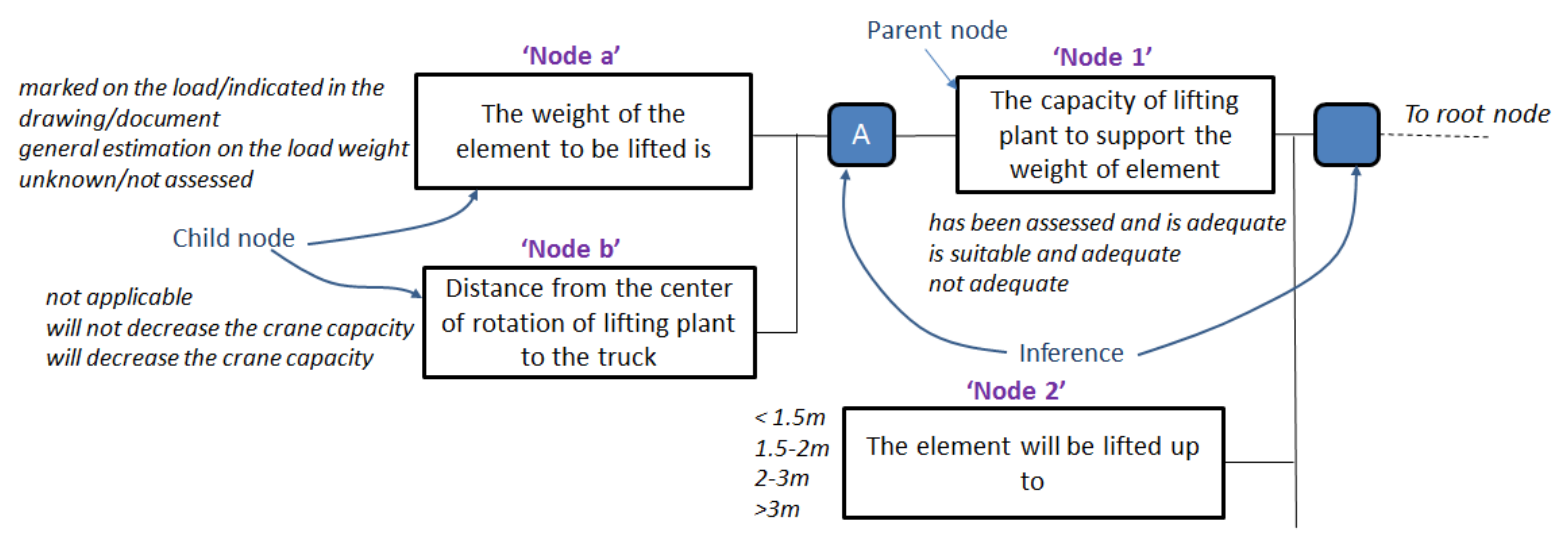

Figure 4: Child node and parent node in the argument tree.

(iii) Assigning linguistic value and numerical value for each node

A set of linguistic values with numerical values are assigned to each node of the argument tree, regardless of its position (Figure 5). These values are relevant to the design options available to a designer when making a judgement on aspects of design that are pertinent to the OSH risk of delivery of the component. These values are important as they reflect relative influence weightings, which could determine the final OSH risk level at the end of the argument tree. Initially, the values were assigned by the researcher based on general knowledge and guidance from the document analysis materials. After having developed the structure of the tree, the next step is to establish the inference procedure. 


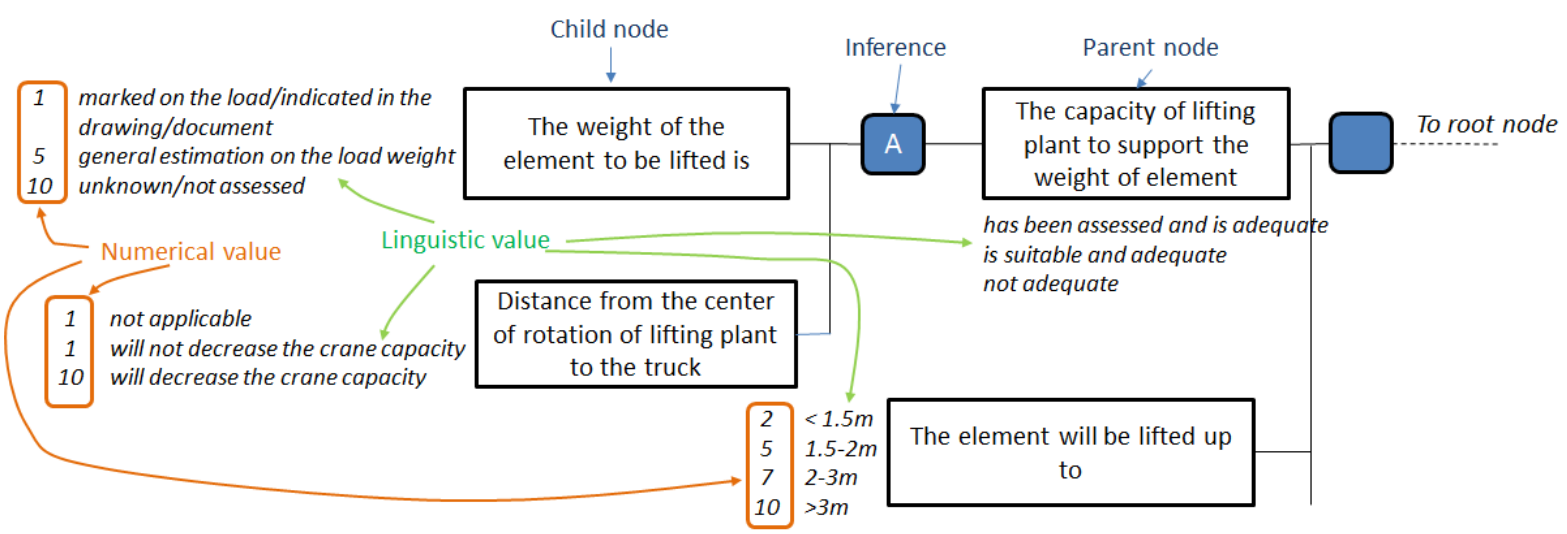

Figure 5: Assigning linguistic and numerical value

(iv)

\section{Inference procedure}

The inference procedure involves deducing the design options represented by the nodes to eventually provide the risk rating for each of the damaging energies. For example, as shown in Figure 6, there are two numerical values at the parent nodes, represented by purple and green cells. The left one (purple cell) indicates the summation range of the numerical values of the child nodes, whereas the right one (green cell) represents the numerical value inferred from the child nodes. The summation value of child nodes will determine the numerical value of parent node.

For example (see Figure 6, inference A):

(i) if the summation of child nodes lies between 0 to 6 , the numerical value will be 1 ; or

(ii) if the summation of child node is between 7 to 12 , the numerical balue of parent node will become 7; or

(iii) if the summation node is equal to and more than 13, the numerical value of parent node will become 10 .

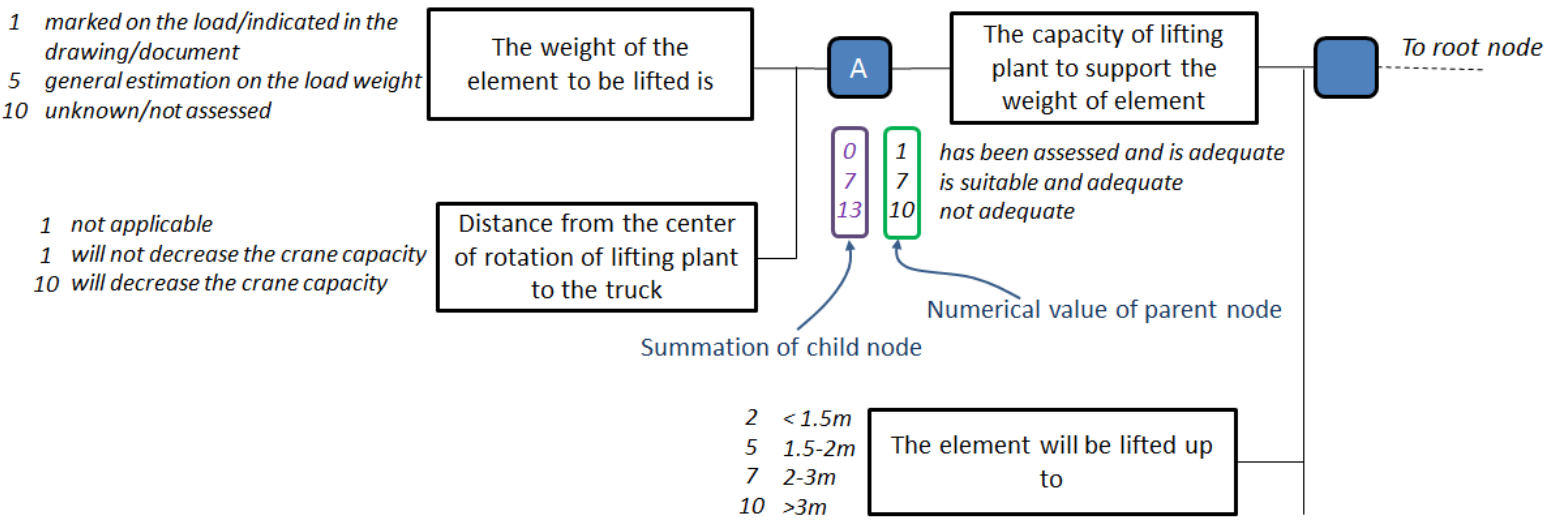

Figure 6: Inference procedure

As an example of the inference procedure (see Figure 7), suppose one particular construction process is executed using a blockwork system which uses a forklift for loading the elements (blocks) onto the truck, and the scenario is as follows:

i) The weight of the elements to be lifted is 'generally estimated on the load weight'. Therefore, the numerical value for this node is ' 5 '.

ii) The distance from the centre of rotation of the lifting plant to the truck is 'not applicable, because this node is applicable to the crane only'. Therefore, the numerical value for this node is ' 1 '. 
iii) The parent node is inferred by these two nodes, leading to the summation of the values as ' $5+1=6$ '. The value is within the range of 0 to 6 , therefore the value of the parent node, which is 'The capacity of lifting plant to support the weight of the element' is 'has been assessed and is adequate', which gives the value ' 1 '.

For comparison to an alternative, let us suppose a similar construction process is being executed (i.e., using a blockwork system which uses a forklift to load the blocks onto truck). However, this time, 'the weight of the elements to be lifted is unknown', whereas 'the distance from the centre of rotation of lifting plant to the truck is not applicable'. The summation of these two values is 11 , which will infer and give value to the parent node of 7. Unlike the previous scenario, the value of parent node, i.e. 'the capacity of lifting plant to support the weight of the element' for the current scenario is 'not adequate'. This means that, if this scenario is chosen, the OSH risk value for the selected parent node is likely to be higher, compared to the previous scenario.

This inference procedure, denoted by A, continues until the final risk rating is ultimately inferred at the root node (D). The risk rating at the root node indicates whether, all factors considered, the OSH risk associated with a particular damaging energy for a given design is 'extreme', 'high', 'medium' or 'low'. It is measured by calculating the values reflecting design choices or options at each child node.

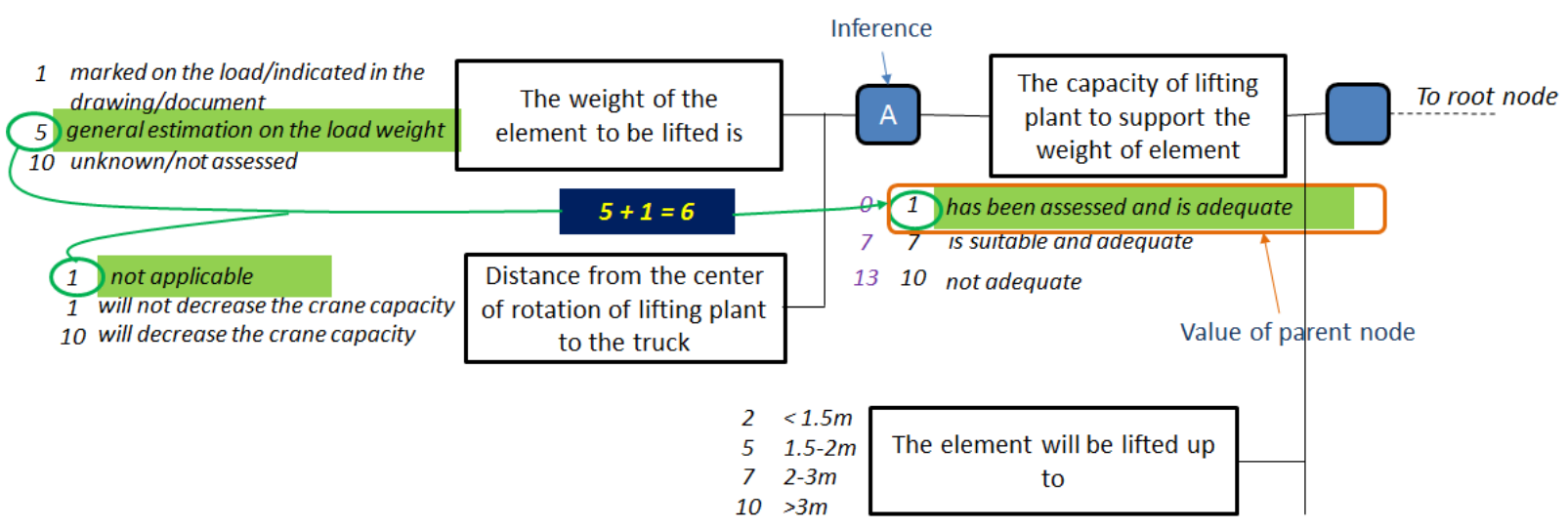

Figure 7: Example of the inference procedure.

Figure 8 shows a complete part of the argument tree, which is related to the gravitational damaging energy for loading the components or materials onto the truck. Linguistic and numerical values are then assigned to each node, pertaining to the design options available for designers when making a judgment about the aspects of their designs. The inference procedure, as indicated by A, $\mathrm{B}, \mathrm{C}$ and $\mathrm{G}$ in the tree, will ultimately give the value of final risk rating. The linguistic and numerical values were initially allocated by the researcher based on analysis of the relevant literature. They were subsequently validated by an expert panel. 


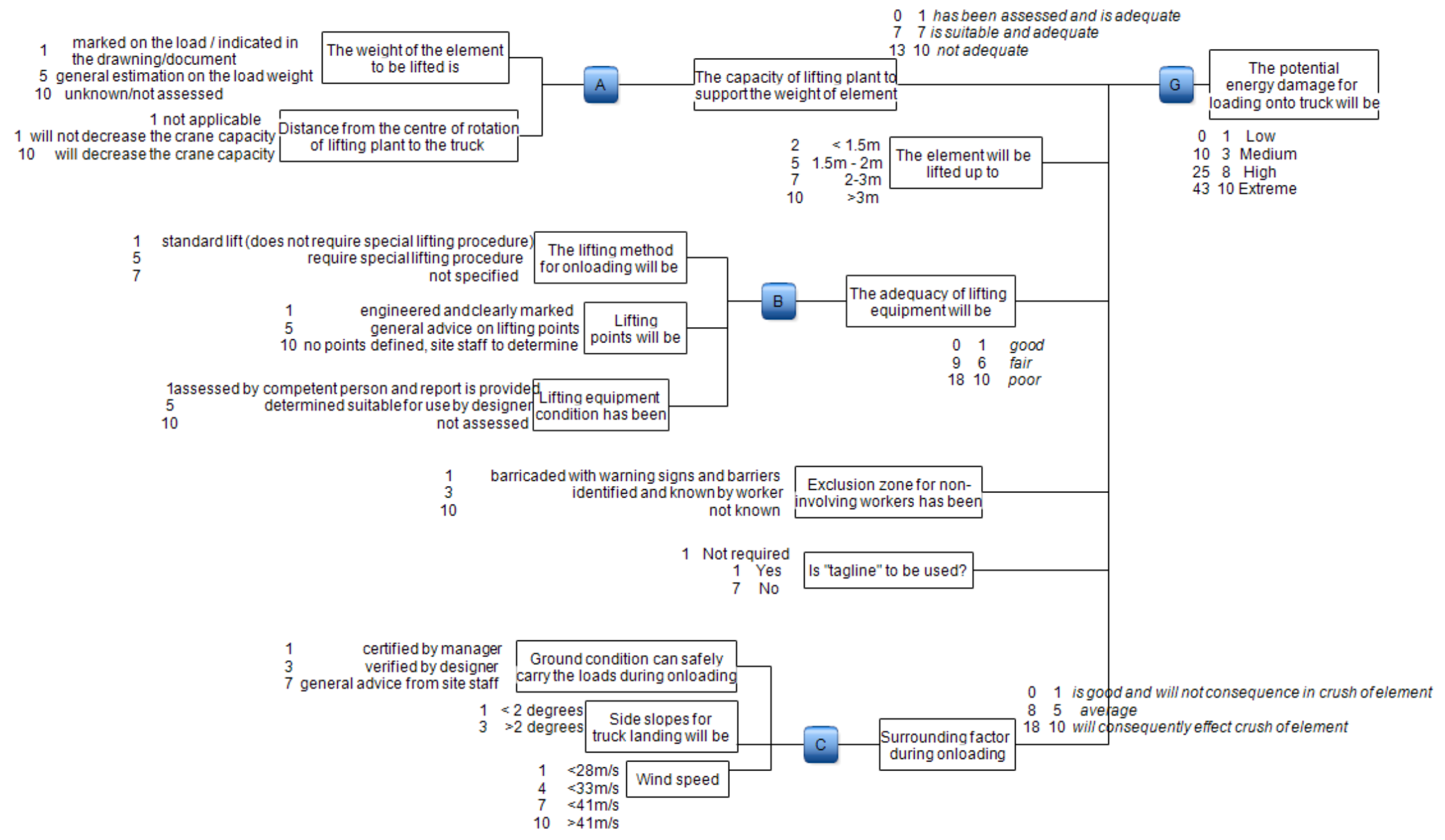

Figure 8: Argument tree showing the inference procedure of the potential damaging energy for loading components or material onto a truck 


\subsection{Validation of the model}

Scenario testing using subject matter experts was undertaken to validate the model. A set of five scenario cases containing knowledge from the trees representing different damaging energies in different construction processes were developed. Each case scenario was assigned with two different scenarios. An expert panel's judgement was obtained to see whether or not their ratings on the scenario cases match the tool-generated scores. In this validation, 12 experts were invited to participate. The experts were from various backgrounds and were chosen based on one of the following criteria: (i) having experience in construction projects, and (ii) being responsible for safety in their organisation. The participants held various positions such as safety and health officer, engineers and safety managers and were responsible for safety and health at their workplace. More than half of the participants have working experience in OSH more than 5 years.

The experts were provided with photographs (for each case), the description of the activities carried out related to the photos and a description of the construction scenario. The experts were then asked to rate the OSH risk of these activities based on the scenarios given on a scale ranging from 1 to 10. The ratings were: $1-2$ (if the experts think the risk is low), 3-7 (if the experts think the risk is medium), 8-9 (if the experts think the risk is high) and 10 (if the experts think the risk is extremely high). The experts were also asked to provide a reason for their choices using their own words. These comments were useful for the researcher to obtain additional information from respondents' insights that may have been overlooked during the development of the argument trees.

The expert panel's judgement results were compared with those of the tool's inferred risk ratings to determine the consistency of risk ratings between both approaches $( \pm 1$ proximity between participants' mean score and tool-generated score). Such consistency provides evidence that the knowledge contained in the model is valid. The statistical method, 'inter-rater agreement (IRA)' was used to examine the within-group homogeneity between participants on their perceptions of the risk rating for each scenario. Using the IRA test, the within-group consensus is deemed to exist if $\operatorname{rwg}(\mathrm{j}) \geq$ 70.

Table 4 summarises the results of both content validity and IRA analysis. As can be seen from the table, the mean values given by the participants for content validity analysis generally show a similar trend to those of the tool. For the cases where the IRA score was high, there seemed less difference between the tool-generated risk score and the mean score of participants (C1S1, C3S1 and C5S2). On the other hand, when there was less agreement between participants, it seemed that there was most discrepancy between the tool-generated scores and the participants' mean scores. The difference in scores for some case scenarios are marked, especially C1S2, C2S2, C4S1 and C4S2.

One important factor that could cause the distribution of score was the type of risk involved in the scenario case. It was observed that participants tended to rate risks according to the outcome, in particular whether the effect is immediate or delayed. An example of the immediate effect type of risk is a 'fall', whereas a delayed type of risk is 'skin disease' (Lingard \& Holmes, 2001). In this study, risks such as falls and being struck by an object, as seen from the participants' mean scores presented in Table 4 , were rated higher than those from tools, whereas delayed effect risks such as chemical exposure and vibration were rated lower than those from tools. Exposure to damaging energies, such as chemicals and vibration poses the risk of delayed health effects that only manifest some time after exposure. For example, vibration activity takes time to cause pain or affect a worker's ability to do his job. Therefore, some participants may not perceive this risk in the same way as the risks with immediate effects and thus decrease its risk rating. This is in line with a study carried out by Holmes et al. (1999), which showed that participants were more concerned with immediate effect risks (such as falling from height) than delayed effect risks, such as developing a skin disease due to chemical exposure.

Besides that, for acute/dread type risk, participants tended to have more agreement on the risk rating, whereas for chronic uncertain risks, there was less consensus among participants on the IRA score. This is shown in Table 4 where for dread-type risks like fall and struck-by, participants apparently rated the risk higher than the tool, whereas for the delayed-effect risks like chemical exposure and vibration, participants rated these lower than the tool. The results also suggest that the model works better for some types of risk than for others. 
Table 4: Results of validation using scenario testing.

\begin{tabular}{|c|c|c|c|c|}
\hline Case scenario & $\begin{array}{c}\text { Type of damaging } \\
\text { energy/risk }\end{array}$ & $\begin{array}{c}\text { Tool- } \\
\text { generated } \\
\text { score }\end{array}$ & $\begin{array}{c}\text { Mean score from } \\
\text { expert panel }\end{array}$ & $\begin{array}{c}\text { IRA between } \\
\text { participants }\end{array}$ \\
\hline Case 1 Scenario 1 (C1S1) & Gravitational/ & 8 & 8 & 0.76 \\
\hline Case 1 Scenario 2 (C1S2) & crush of panel & $1(3)$ & 4 & 0.39 \\
\hline Case 2 Scenario 1 (C2S1) & Kinetic/struck-by & $3(3)$ & 4 & 0.59 \\
\hline Case 2 Scenario 2 (C2S2) & vehicle or load & $10(5)$ & 6 & 0.14 \\
\hline Case 3 Scenario 1 (C3S1) & Chemical/chemical & $\mathbf{3}$ & $\mathbf{3}$ & $\mathbf{0 . 8 3}$ \\
\hline Case 3 Scenario 2 (C3S2) & exposure & $8(8)$ & 7 & 0.43 \\
\hline Case 4 Scenario 1 (C4S1) & Vibration/vibrating & $8(3)$ & 3 & 0.90 \\
\cline { 1 - 1 } Case 4 Scenario 2 (C4S2) & & $10(8)$ & 6 & 0.52 \\
\hline Case 5 Scenario 1 (C5S1) & Gravitational/fall & $3(5)$ & 4 & 0.36 \\
\hline Case 5 Scenario 2 (C5S2) & from height & $\mathbf{8}$ & $\mathbf{8}$ & $\mathbf{0 . 7 7}$ \\
\hline
\end{tabular}

The scenarios that generated high inter-rater agreement, and consistency between expert judgements and model inferences are demonstrated to be high in validity and appear to be robust. However, some scenarios did not achieve this level of agreement. This means that these trees cannot be considered valid at this stage and require additional development. The additional insights provided by the experts allowed for refinements to the relevant model to be made to increase the future validity of risk-rating inferences.

Amendments are made on the linguistic and numerical values in the argument trees, such as revising the information in the child node with more appropriate words. This is done to ensure accurate and understandable information is communicated to the designer reading the tree. There also some numerical values changed to more accurate values, based on the experts' insights. Meanwhile, for delayed type of risk, some numerical values were maintained regardless of the participants' perceptions because the effect is long term, and the awareness of its severity is often neglected (Holmes et al., 1999). This risk should also be treated appropriately as the effect could cause serious chronic illness. For instance, for workers who are involved in vibrating the concrete, the scenario may provide a low-risk vibration effect, but there are many activities that could have more severe consequences in the long run. Finally, the values at the final risk rating (root node) are supplemented with one more value, namely ' 5 ' which is placed in the middle of the value range to provide more accurate risk rating.

\subsection{Demonstration of the application of the model}

In order to demonstrate the application of the model, a mock trial study was conducted, which provides a realistic opportunity to field test the model, and thus visualize the workability of the model. The mock process was done on the existing cases utilised during the model development. It is acceptable to use the existing cases because these cases were previously used to collect data and information about the process and the risks associated with the process - but not to rate the risk. The information from the case studies was used as if it were the designer's choice of process design arising from discussions made in the design stage. Figure 9 depicts an example of the potential gravitational energy risk profile generated by the tool for the steps of the process involved in the selected construction approaches. The $\mathrm{x}$-axis presents the process steps involved, whereas the y-axis presents the risk magnitude. The lines which plotted the graph represent the selected construction approaches used as case examples for this study.

In general, evaluation of existing cases reveals that the potential gravitational damaging energy of the process during the manufacturing stage is relatively low. For the precast frame system, evaluation of the process of component lifting, such as 'transfer components to storage', relates to a precast concrete column. For the beam, the weight of the component depends on whether it is a precast concrete beam with a normal reinforcement bar or prestressed concrete. If it is normal precast concrete, then the weight is much greater, as the reinforcement bars are larger. The weight of the component is important, as it is one of the design factors that determine the risk level in the argument tree.

Evaluation of existing cases shows that the gravitational damaging energy risk is high in certain construction approaches, especially with in-situ concrete and the masonry method, because, during the time of observation, inappropriate measures were taken during delivery. For example, the bricks were not stacked properly on the truck, which could potentially destabilise the truck and cause it to overturn. Further, offloading the bricks at the construction site might have caused the bricks to fall and injure the 
worker. However, this scenario may not have happened in other projects, as usually the bricks are arranged on the pallet and wrapped, therefore reducing the potential of crushing. It is also to be noted that designers cannot be responsible for poor work practice on site. For other construction approaches, such as the wall panel system, the precast frame system and the panelised system, the components were often arranged appropriately in accordance with guidelines, and properly secured. 
Evaluation of gravitational energy for existing case studies

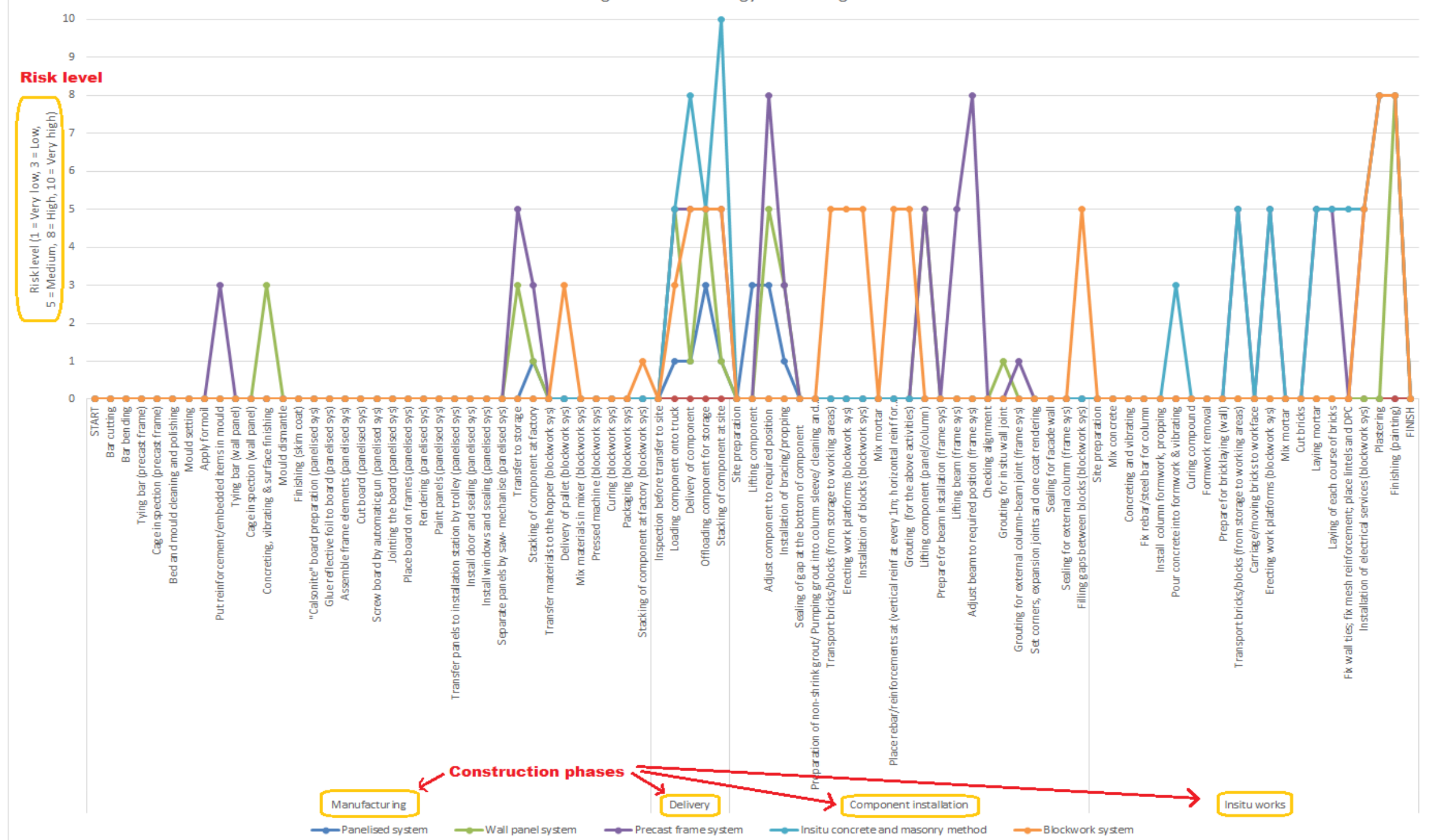

Figure 9: Example of the evaluation of the model for gravitational energy 
Particularly noticeable are changes to risk over the different steps of the construction processes. This provides evidence that there is a difference in the profile of OSH risk between IBS construction (i.e. panelised system, wall panel system, precast frame system and blockwork system) and the traditional method (i.e. in-situ concrete and masonry) and that these change as work progresses through its component activities. The magnitude of OSH risk for each activity from the damaging energy perspective is also estimated using the tool. The development of this tool demonstrates that it is possible to pick up differences in the risk magnitudes of particular activities between various construction processes. In addition, the tool provides information on 'where is the risk?', 'what type of risk is it?', and 'how bad is the risk?' for each construction approach. The tool also enable design decision-makers to practically compare and to facilitate decision-making and support accident prevention.

Demonstration of the risk profile for delivery activity is shown in Figure 10 (partially extracted from Figure 9). Note that the risk profile of the construction approaches for the entire construction process is provided for single-storey evaluation only, for generalization.

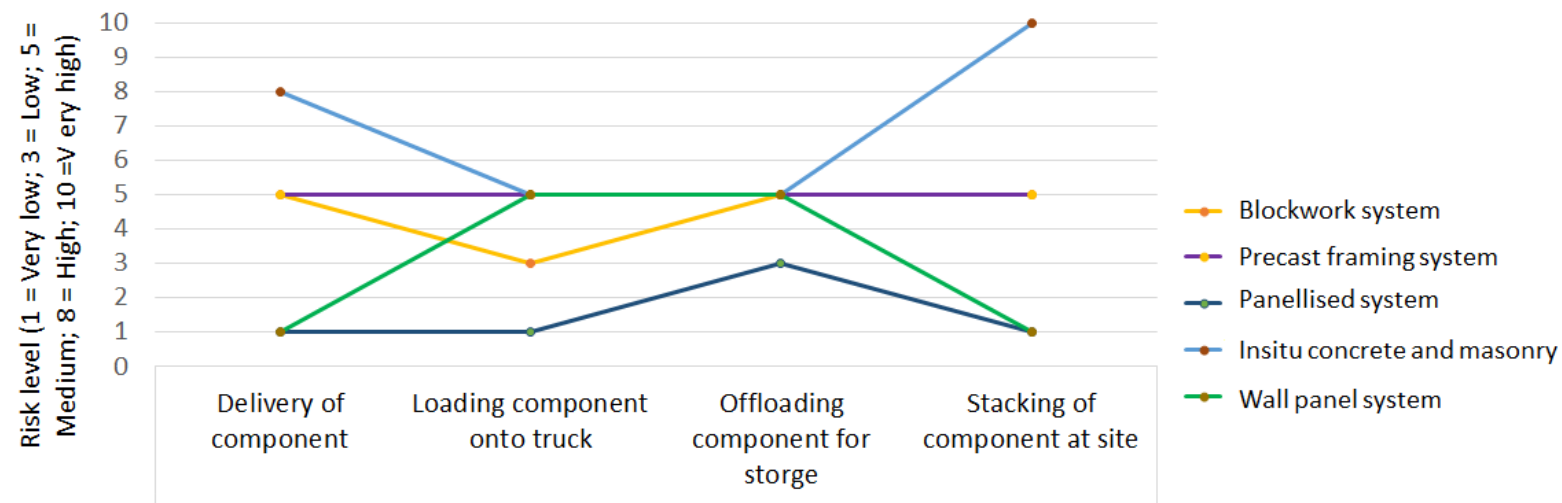

Activities involved in delivery phase

Figure 10: Example of the evaluation of the model for gravitational energy during delivery stage

Looking at the delivery stage in detail, the potential for gravitational damaging energy exists in all construction processes, in which its magnitude is depends on the design options chosen in the argument trees. The height of the component lifting from the ground is among the main factors that determine the potential gravitational damaging energies, therefore this design element needs to be chosen carefully to control the risk. For example, the panel which is lifted at less than $1.5 \mathrm{~m}$ height from the ground is less likely to cause serious injury, in contrast with the panel which is lifted up to $3 \mathrm{~m}$ from the ground. Therefore, even if an accident happens, such as crushing of the panel and causing injury/damage, the lower height of the panel is likely to reduce the impact.

The weight of the component is important, as it is one of the design factors that determine the risk level in the argument tree. For example, in panellised system, evaluation shows low level of risk magnitude, particularly during 'loading of component onto truck'. This is because, the weight of panel is much lighter compared to other approaches, such as precast concrete wall panel and beam. Evaluation of the existing case studies also shows medium risk of gravitational damaging energy for all construction approaches, except in situ concrete and masonry method. In situ concrete and masonry methods were assessed to possess noticeably higher gravitational damaging energy than the others, as indicated in Figure 9. By contrast, the wall panel system and panellised system was assessed as not carrying a high magnitude of risk.

Meanwhile, Figure 11 and 12 show the difference that some inputs can make for the same project using the same energy. For example, if the designer decides to reduce the gravitational damaging energy for the activity of 'adjusting beam to required position' in the component installation stage of the precast frame system (the risk level for this activity is high). The original design factors selected for the case are shown in Figure 11. Looking back at the related argument trees, the designer may choose which design factors he or she wants to modify. However, the 'height of lifting distance' is difficult for the designer to modify since it depends on the floor level to which the component will be lifted. Design 
factors that are capable of modification are those relating to 'the adequacy of temporary base restraint provided for precast element', 'the adequacy of brace footing concrete to attain the load' and 'the temporary barrier/guardrail installed'. The designer may modify any of these factors to get his/her desired risk level. For example, if the designer wants to modify the factor of 'the temporary barrier/guardrail installed', substituting less risky design options for this factor can reduce the damaging energy (Figure 11). The new calculated gravitational damaging energy for this particular activity changes to 'medium'.

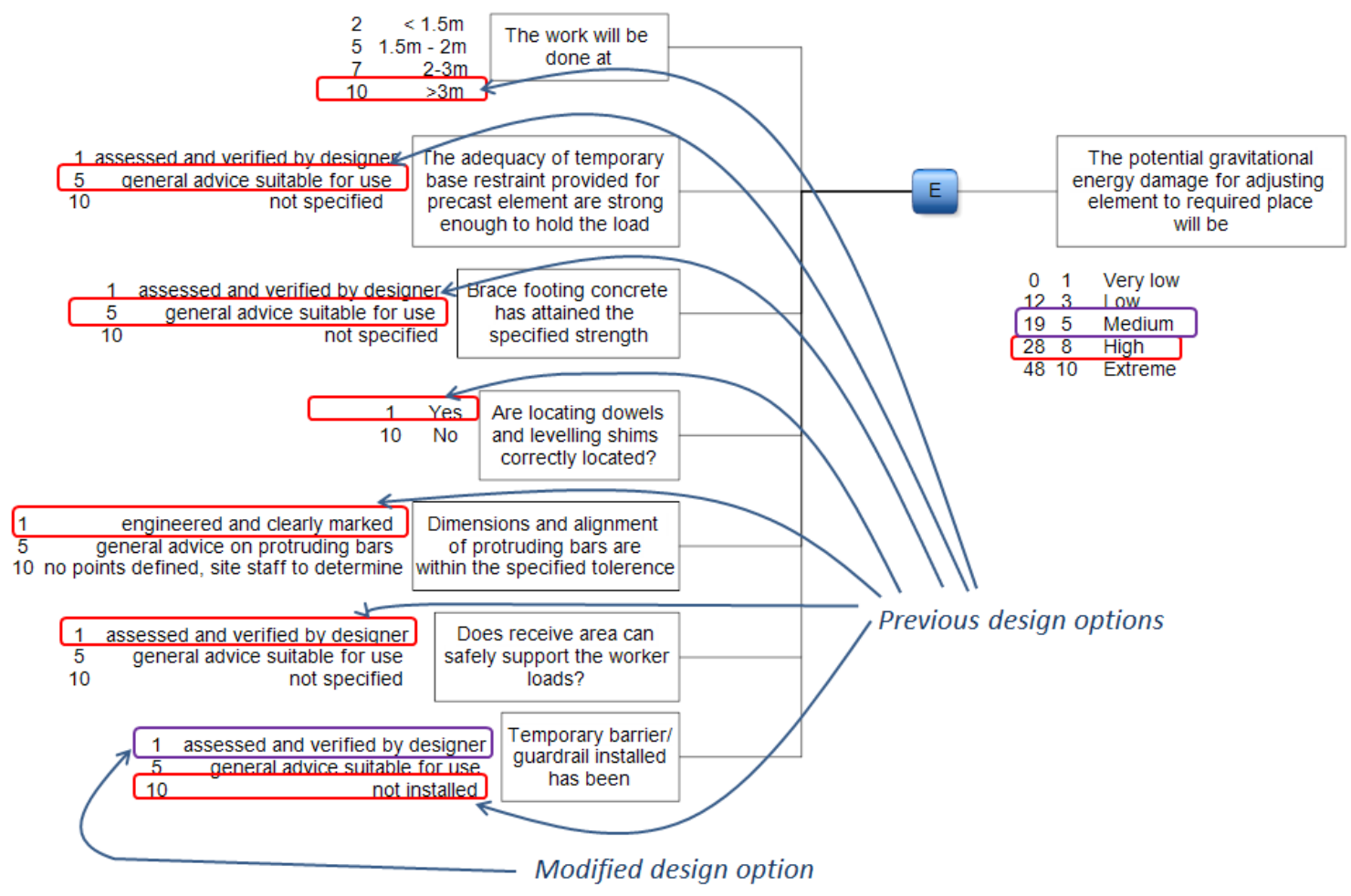

Figure 11: Selection of design options to reduce the risk

Evaluation of gravitational energy for precast frame system

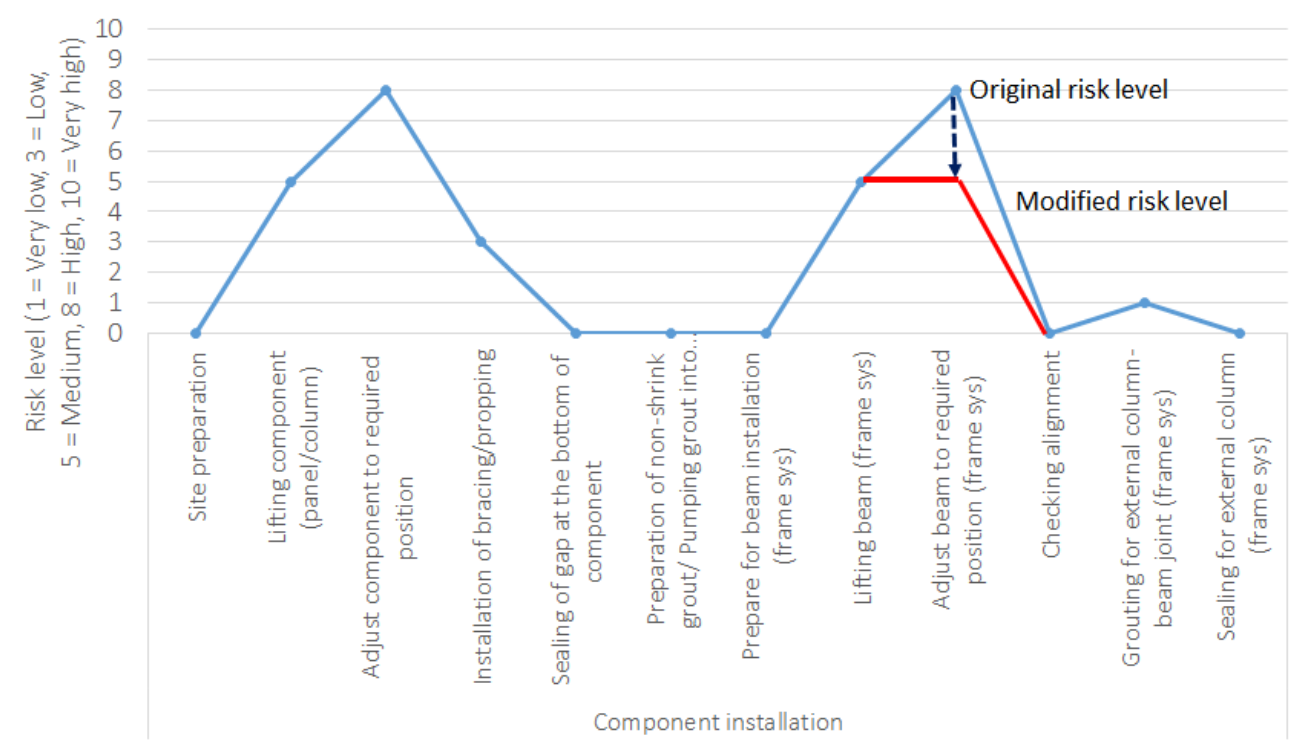

Figure 12: Example of modifying the argument tree to a lower risk level

\subsection{Discussion}


The knowledge-based energy damage model developed in this study is complex because it does not consist of 'pure energy' solely; in fact, it includes other relevant factors pertinent to the measures taken during the construction process. The term 'pure energy' here refers to the original definition of the potential energy, which is more related to the field of physics. Potential gravitational energy is an energy stored in an object and this energy has the potential to do work, represented with $\mathrm{U}=m g h$ (calculated in joules). For example, during loading the component onto the truck, the only factor relevant to pure energy is 'the component is being lifted up to how many meters (height)'. Therefore, in order to address this limitation, this study includes other related factors that are relevant to the gravitational energy in developing the design factors which have an impact to the gravitational damaging energy. This is to ensure that the knowledge within the argument tree is deemed sufficient.

\subsection{Argument trees (tool) output and features}

The argument trees were divided into sections according to the type of the damaging energies in each construction stage due the relatively high number of design issues identified as being relevant to the damaging energies. This enables comparison to be made about whether the exposure to different damaging energies varies between construction approaches: for example, one approach might reduce gravitational energy risk, but increase chemical energy risk. Structuring the knowledge in this way permitted the exclusion of certain design features that, if they were not included in the design, could be eliminated at the early stage of the risk assessment (Cooke et al., 2008). This is due to the fact that the damaging energies do not all exist at the workplace at the same time. For example, in the manufacturing of components, vibration energy during concreting would only be present if the work were not fully automated, whereas radiation energy could be totally eliminated if the work were done in a closed area. Thermal energy, for instance, may only be present if the work involves cylinder gas, exposure to heat or UV, hot work etc. These considerations are acknowledged by the author, and careful consideration was taken when developing the argument trees.

To overcome this, a confirmation box is assigned to confirm certain design inclusions prior to undertaking the risk assessment. This can be seen in Figure 13, where the confirmation box is shaded. For example, the activity of 'putting reinforcement in mould' in the manufacturing phase can be done either manually or automatically (by machine). If the activity is done by workers (manually), then there is no requirement to assess the potential 'gravitational' energy damage since the risk of the gravitational damaging energy can be zero or relatively low. Other activities which also have the same confirmation requirement during the manufacturing stage include 'putting reinforcement in cages' for kinetic energy, 'concreting, vibrating and surface finishing' for chemical energy, 'concrete vibrating' for vibration energy, and 'bar cutting' for electrical energy. Note that the confirmation requirement is only involved in the manufacturing stage since the activities are done at the factory/fabrication yard where the process may be fully automatic or semi-automatic.

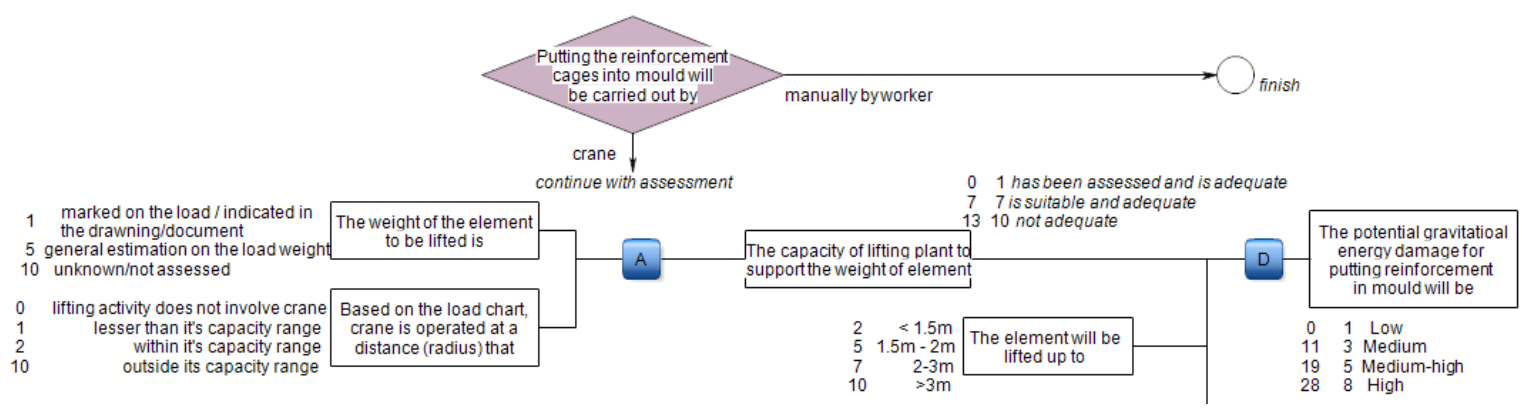

Figure 13: Example of the confirmation of design inclusion prior to assessing the tree

In addition, the in situ concrete and masonry does not involve a manufacturing stage, therefore the assessment of the damaging energies presented by the manufacturing process can be easily omitted from the consultation, and the designers who opt for this construction approach will need to proceed to the assessment of the 'delivery' stage. Moreover, factors like 'training of the workers' and 'experience of the crane operator', for example, were not included in the argument trees. This is because these factors are irrelevant to the 'designing for safety' concept, where the designer has no influence over the factors. 


\subsection{Significance of the tool}

Since the development of the argument trees in this paper were underpinned by the concept behind ToolSHeD, it is important to distinguish the two so that the uniqueness of the created tool can be recognised. In general, the argument tree models developed in this study differ from those of ToolSHeD in two ways: 1) they are process design tools rather than product design tools - a major new development; and 2) they incorporate energy damage rather than a pure hazard approach, which are explained in the paragraphs below.

\section{(i) Process-focused assessment tool}

The argument tree developed in this study is a 'process' OSH assessment model, which is different from ToolSHeD as it was 'product' driven. The process design risk assessment lies in assessing risks (potential damaging energies) based on the process involved within the construction approach. The process was depicted by the activities involved in the construction process that create different particular potential damaging energies for particular activities within the process. This therefore provides an overview of the OSH risk rating for multiple construction approaches based on the designers' chosen design. This is important because the comparison of OSH performance for different construction approaches will assist sensible comparison and evidence-based decision making. Therefore, instead of changing their design options to reduce risk, designers can opt to change to another construction approach which they think is suitable and produce less risk. This also reflects process design, which provides ideas for designers regarding the selection, before construction begins, of suitable construction approaches to be executed during construction. The designers need to decide how the construction work will be done, and once they achieve the risk rating of their design decisions, they must then determine whether to continue with the selected construction process, reduce the risk, or change to another construction process. This entire procedure reflects the incorporation of safety during the design stage. When the designer incorporates safety during the design stage, the elimination or reduction of hazards during construction could improve safety performance (Zhang et al., 2015; Behm, 2005).

\section{(ii) Incorporate energy damage}

The risk assessment model developed in this study is not articulated from pure risk; rather, it incorporates the energy damage model concept, thus changing the terms used to indicate 'hazard/risk' within the argument tree. Using damaging energies concept in the risk assessment model gave the model a more robust theoretical framework than was present in ToolSHED.

In order to assess the construction OSH risks within a design stage, knowledge is needed about the damaging energies and energy transfer mechanisms associated with the construction processes. Further, the identification of barriers to prevent such energies from injuring or damaging in energy transfers can then be transformed into argument trees. Each design factor assigned in the tree somehow contributes to the level of damaging energy, with several design options designated as either reducing or raising the level of risk. Therefore, the combination of the design factors within the tree, which represents the modelling of expert reasoning, does help designers to compare risk outcomes against predetermined levels of acceptability.

\section{(iii) Allow for generating risk profiles}

The argument tree model developed in this study departs from ToolSHeD in that the sections of argument trees do not constitute components of the complete tree. Indeed, these sections are left isolated from one tree to another to represent the various potential damaging energies of each activity in the construction process. In this way, the tool can generate the risk profiles of the damaging energies throughout the construction process, from start to finish.

This model also differs from other risk assessment models developed by scholars such as HASPREST (McKay, 2010) and Gangolells et al. (2010), that are generally static and unable to present risk profiles over time. As the risks change continuously, this model makes a contribution by dealing with the absence of this aspect in other risk assessment models. The argument trees are assigned several design options, which provide different risk levels to deal with the probability of changes of risk. This proves the contribution of the present model. Even though Hallowell \& Gambatese (2009) have developed activity-based risk profiling, which can evaluate the safety risk impact of alternative means 
and methods of construction, the approach used to develop the method of quantification is different from the tool developed in this study. In Hallowell \& Gambatese (2009), the safety risk impact was determined from the unit data provided from the previous pre-determined quantitative frequency and severity components of safety risks, along with the expected task durations (in worker-hours). Besides that, the method developed by Hallowell \& Gambatese (2009) was intended for concrete formwork construction only, rather than the whole life cycle.

Moreover, the argument trees were developed to cover the multiple categories of damaging energies within construction processes, thus allowing the tool to take a multiple-risk view in the process. Aside from showing how the particular risks (damaging energies) change within the process during a construction life cycle, the risk profile evaluation can also generate a view of multiple damaging energies for a particular construction approach. Figure 13 shows an example of the evaluation of multiple risks for a column-wall panel system approach. The multiple-risk view allows designers and other construction stakeholders to get an idea of the level of multiple damaging energies for an activity and compare the different risk levels of the damaging energies for each activity. For example, during the activity of 'bar cutting' and 'bar bending', the risk of vibration energy is higher than electrical energy. Therefore, designers can make judgements on how they want the activity to be undertaken, whether to stick with the initial decision, or choose to reduce the amount of vibration energy by changing their design decisions in the argument tree. Designers can also make a case for a particular construction approach in which damaging energy is the highest and requires the greatest attention for risk treatment.

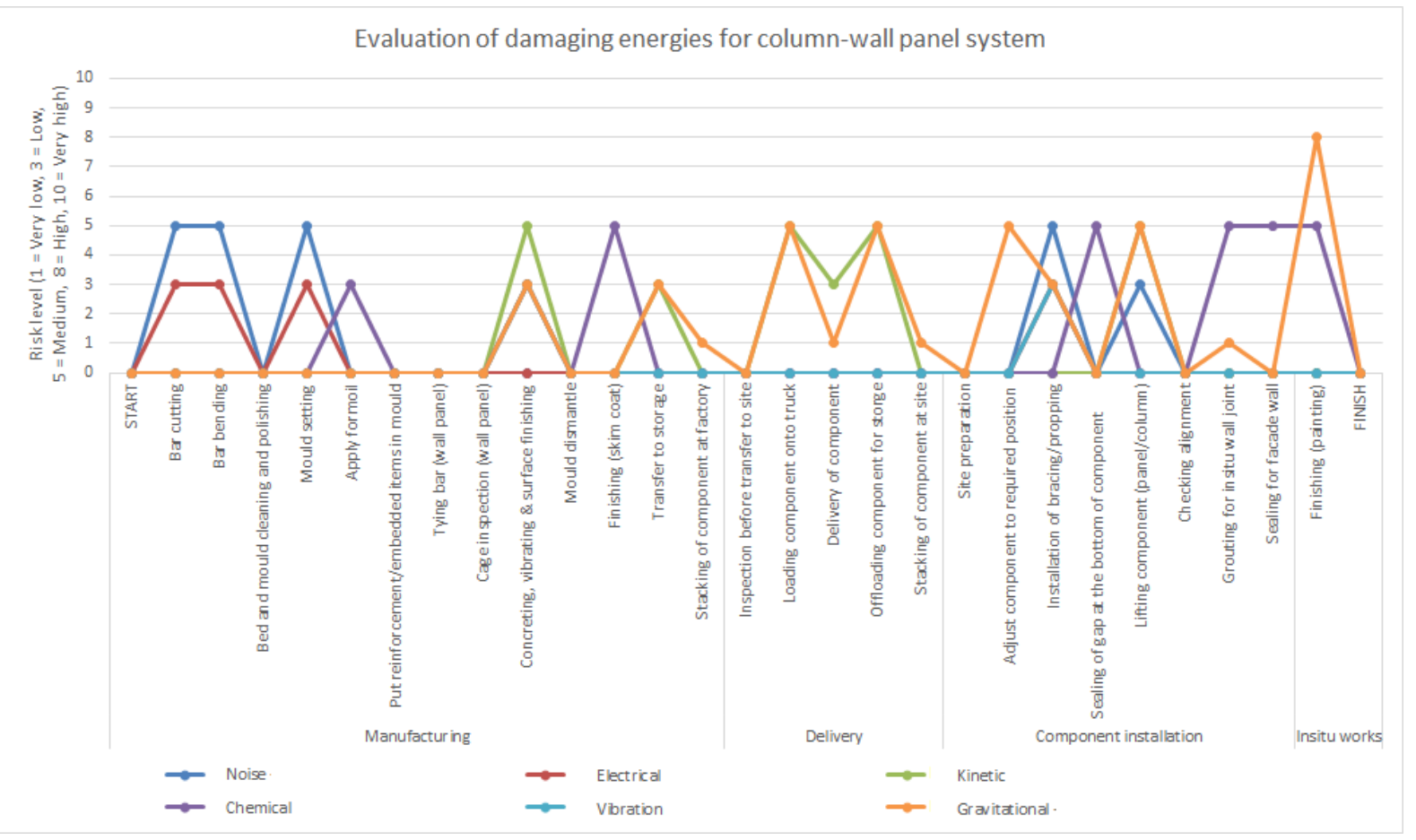

Figure 13: Example of multiple-risk view of column-wall panel system

\section{Conclusion}

This paper presents the development of a knowledge-based energy damage risk assessment model to assess OHS risks inherent in construction processes. The model was developed by using a combination of 'argumentation theory' and the 'energy damage model', building on a risk assessment tool named ToolSHED. The development process of the model, together with the matters related to the significance of the created tool, has been discussed above. Given the relatively high number of design issues identified as being relevant to the potential for damaging energies, the argument trees developed in this study were divided into sections according to the type of damaging energies and the construction stage involved. The argument trees developed represent the hierarchy of factors relevant to the 
assessment of a design-related OHS risk, where the risk rating (potential damaging energy) is the root node at the top of the trees and is denoted by the linguistic variables 'extreme', 'high', 'moderate' and 'low', used to denote the magnitude of the OHS risk, flowing from a series of cumulative design decisions. The development of the argument tree/risk assessment model in this study sought to deal with the flaws in existing risk assessment methods, in order to determine the relative safety of different construction processes. In this study, the system (model) is breaking down the process into its component parts so that the potential risks can be evaluated according to these components. The risk levels can be evaluated and shown in the risks profiles. The risks profiles also show the changes of risks when the construction process is transitioning from manufacturing to site, therefore providing a sophisticated way of doing risk assessment compared to traditional risk assessment which does not cope with the changing activity inherent in construction work. The development of this tool also contributes to filling the gap in designing for process safety, which is still lacking in both academia and industry.

The strength of the methodology lies in fact that it provides a mechanism for the relative comparison of hazards of different construction approaches. The tool enables a risk profile to be generated across different phases of a process, thereby providing powerful assistance to designers and contractors. Currently, OSH is considered post-design, and therefore options for hazard elimination are largely removed. This tool offers scenario testing in earlier design phases, so that OSH can inform design, rather than the current approach in which OSH bears little influence over design. Therefore, whether the option is an IBS or traditional approach, the fundamental idea of the model is to motivate construction designers or decision-makers to address safety in the design process and encourage them to examine carefully the probable OHS risk variables surrounding an action, thus preventing accidents in construction.

This study provides additional contributions to knowledge on understanding IBS or offsite construction risks. The findings revealed various types of risks associated with the IBS or offsite construction process. Moreover, the use of this model can provide a mechanism for the relative comparison of hazards of different construction approaches. The tool enables a risk profile to be generated across different phases of a process, thereby providing powerful assistance to designers and contractors. Currently, OSH is considered post-design, and therefore options for hazard elimination are largely removed. This tool offers scenario testing in earlier design phases, so that OSH can inform design, rather than the current approach in which OSH bears little influence over design. Therefore, whether the option is an IBS/offsite or traditional approach, the fundamental idea of the model is to motivate construction designers or decision-makers to address safety in the design process and encourage them to examine carefully the probable OSH risk variables surrounding an action, thus preventing accidents in construction.

This study has limitation that relates to the breadth of knowledge and generalizability since it is limited by the IBS types for case study data collection. As the data collection was primarily done in Malaysia, this research only covers the non-volumetric system due to the absence of the volumetric system within the scope of IBS in Malaysia. Future research can use the data from other studies, such as an international case study, to execute the research and to include it in the argument trees.

Another limitation relates to the limited types of damaging energies covered in this study. As this study only focused on the major hazards involved in building construction, it incorporates only five main types of damaging energies to develop the argument trees: gravitational, kinetic, chemical, electrical, and noise. This research does not include the damaging energies of body muscle energy, mechanical power energy, and thermal energy as these types of damaging energies are not categorized under major hazards. The determination of major hazards was justified from the analysed accident types found in previous study. Future research should include the remaining damaging energies in order to develop a tool that is robust and to examine the effect of the damaging energies on the activities and processes undertaken. This provides for a more reliable tool and more comprehensive knowledge.

\section{References}

Abas, N.H., Blismas, N. and Lingard, H. (2011), "Development of a Knowledge-Based Energy Damage Model to Assess Occupational Health and Safety (OSH) Construction Risks in Malaysia", paper presented at CIBW099 Prevention: Means to the End of Construction Injuries, Illnesses, and Fatalities, 
Abas, N.H., Blismas, N. and Lingard, H. (2016), "Knowledge-Based Energy Damage Model for Evaluating Industrialised Building Systems (IBS) Occupational Health and Safety (OSH) Risk", MATEC Web of Conferences, Vol. 47, 04015.

Abas, N.H., Najib, M.N.M., Deraman, R., Hasmori, M.F., Tong, Y.G. and Rahmat, M.H. (2018), “The Effect of Industrialised Building System (IBS) Construction on Worker's Safety and Health", Tong, Y.G., Rahmat, M.H. and Abas, N.H. (Ed.s), Issues in Built Environment, Penerbit UTHM, Johor, Malaysia, pp.55-67.

Abas, N.H, Yap, W.H., Mohammad, H., Yaman, S.K. and Rahmat, M.H. (2020), "The Analysis of Struck-By Accidents at Construction Sites in Johor", International Journal of Integrated Engineering, Vol. 12, 266-275.

Abdullah, D.N.M.A. and Wern, G.C.M. (2011), "An analysis of accidents statistics in Malaysian construction sector", 2010 International Conference on E-business, Management and Economics IPEDR vol.3, IACSIT Press, Hong Kong, pp.1-4.

Arkerkar, R. A., and Sajja, P. S. (2010), Knowledge-Based Systems. Jones and Barlett Publishers, USA Ayob A., Shaari A. A., Zaki M. F. M., \& Munaaim M. A. C. (2018), "Fatal occupational injuries in the Malaysian construction sector-causes and accidental agents". IOP Conference Series: Earth and Environmental Science, Vol. 140, 012095.

Behm, M. (2006). An Analysis of Construction Accidents from a Design Perspective. The Center to Protect Workers' Rights, Silver Spring, MD.

CIDB (2007), "Construction Industry Master Plan (CIMP 2006-2015)", Construction Industry Development Board (CIDB), Kuala Lumpur, Malalysia.

CIDB. (2007), Construction Industry Master Plan (CIMP 2006-2015). Construction Industry Development Board, Kuala Lumpur, Malaysia.

Calzada A., Liu, J, Wang H. and Kashyap, A. (2015), "A new dynamic rule activation method for extended belief rule-based system", IEEE Transactions o Knowledge and Data Engineering, Vol. 27 No.4, pp. 880-894

Che Ibrahim, C. K. I., Belayutham, S., Azmi, E. A. and Hussain, A. (2019), "Exploring the knowledge of Prevention through Design (PtD) among Malaysian civil \& structural designers", IOP Conf. Series: Materials Science and Engineering, Vol. 615, 012031.

CIDB (2007), Construction Industry Master Plan (CIMP 2006-2015). Construction Industry Development Board, Kuala Lumpur, Malaysia.

CIDB (2016), "Construction Industry Transformation Program (CITP) 2016-2020", available at: http://www.citp.my/ (accessed 1 February 2019).

Cooke, R. M. (1997). “Uncertainty modelling: examples and issues”, Safety Science, Vol. 26, pp.49-60.

Cooke, T., Lingard, H., Blismas, N., Stranieri, A. (2008), "ToolSHeDTM: the development and evaluation of a decision support tool for health and safety in construction design", Engineering, Construction and Architectural Management, Vol. 15, pp.336-351. 
DOSH (2017a), Guidelines on Occupational Safety and Health in Construction Industry (Management) 2017, Department of Occupational Safety and Health, Kuala Lumpur, Malaysia

DOSH (2017b), "OSH IN CONSTRUCTION—Prevention through Design (PtD)" , available at https://www.dosh.gov.my/index.php/list-of-documents/osh-info/construction-safety/e-

buletin/2017/2382-bil-1-2017-prevention-through-design/file (accessed 1 February 2019)

DOSH (2019). "Fatal Accident Case", available at https://www.dosh.gov.my/index.php/fatal-accidentcase-1 (accessed 20 March 2020).

Evans, J.S.B.T., Over, D.E., Manktelow, K.I. (1993), "Reasoning, decision making and rationality", Cognition, Vol. 49, pp.165-187.

Foo, C.L. (2005), Budgeting For Occupational Safety And Health Management and Its Implementation, Master Builders 1st Quarter 2006 Malaysia, Master Builders Association Malaysia, Kuala Lumpur, Malaysia, pp.10-15.

Gangolelles, M., Casals, M., forcada, N., Roca, X. and Fuertes, A. (2010). "Mitigating construction safety risks using prevention through design", Journal of safety Research, Vol 41, pp.107-122.

Gambatese, J. A., Behm, M. and Rajendran, S. (2008). "Design's role in construction accident causality and prevention: perspectives from an expert panel”, Safety Science, Vol. 46, pp.675-691.

Gibb, A., Haslam, R., Hide, S. and Gyi, D. (2004). 'The role of design in accident causality”, Hecker, S., Gambatese, J., and Weinstein, M. (Ed.s.), Designing for Safety and Health in Construction, Eugene, OR, UO Press.

Ghosh, M.E., Naja, H., Abdulrab, H. and Khalil, M. (2017), "Towards a legal rule-based system grounded on the integration of criminal domain ontology and rules", Procedia Computer Science, Vol. 112 , pp.632-642.

Hamid, A.R.A., Majid, M.Z.A. and Singh, B. (2008), "An overview of construction accidents in Malaysia", Mohamad, M.I. (Ed.), Issues in construction industry, Penerbit Universiti Teknologi Malaysia, Johor Bahru, Malaysia, pp.110-123.

Holmes, N., Lingard, H., Yesilyurt, Z. and Munk, F. De. (1999), “An exploratory study of meanings of risk control for long term and acute effect occupational health and safety risks in small business construction firms", Journal of Safety Research, Vol. 30, 251-261.

Hosseinian, S.S. and Torghabeh, Z.J. (2012), "Major theories of construction accident causation models: A literature review", Int. J. Adv. Eng. Technol., Vol.4, pp.53-66.

Jeffrey, J. and Douglas, I. (1994). "Safety Performance of the United Kingdom Construction Industry", Proceedings of the Fifth Annual Rinker International Conference Focusing on Construction Safety and Loss Control, University of Florida, pp.233-253.

Junid, S. M. S. (1986). Industrialised Building Systems. Proceedings of a UNESCO/FEISEAP Regional Workshop.

Lenat, D.B. (1983), "The role of heuristics in learning by discovery: three case studies", Michalski, R.S., Carbonell, J.G., and Mitchell, T.M. (Ed.s), Machine Learning. Symbolic Computation, Springer, Berlin, Heidelber, pp.243-306. 
Lingard, H. and Wakefield, R. (2019), Integrating Work Health and Safety into Construction Project Management, Hoboken, NJ: Wiley-Blackwell.

Lingard, H., Stranieri, A. and Blismas, N. (2006), "Supporting the design OSH process: a knowledgebased system for risk management”, in Brown, K., Hampson, K., \&Brandon, P. (Ed.s), Clients Driving Innovation: Moving Ideas Into Practice, Co-operative Centre for Construction Innovation, Icon. Net Pty Ltd, Brisbane, Australia, pp.225-234.

Lingard, H., and Holmes, N. (2001). "Understandings of occupational health and safety risk control in small business construction firms: barriers to implementing technological controls", Construction Management and Economics, Vol. 19, pp.217-226.

Liu, J. (2016), "Some clarifications and perspectives of belief rule-based decision model", in Zeng X., Lu J., Kerre E.E., Martinez L. and Koehl L. (Ed.s), Proceedings of the 12th International FLINS Conference, Roubaix, France, 24-26 August 2016, World Scientific Publishing Co. Ltd., Singapore, pp.87-92.

Liu, J., Martinez, L, Calzada, A. and Wang, H. (2013), "A novel belief rule base representation, generation and its inference methodology", Knowledge-Based System, Vol. 53, pp.129-141.

McKay, L.J. (2010), "The Effect of Offsite Construction on Occupational Health and Safety", Loughborough University, Loughborough, United Kingdom.

Misnan, M.S. (2013), Safety management: Implementation, review and audit SHASSIC assessment tools for safety, Universiti Teknologi Malaysia, Johor Bahru, Johor.

Mat Nasir, N., Ismail, Z., Ismail, F., Syed Alwee, S. N. A. and Che Mat, M. (2012). "Enabling Factors Towards Safety Improvement for Industrialised Building System (IBS)", International Journal of Architectural and Environmental Engineering, Vol. 6, 1115-1120.

Rafindadi, A.D., Napiah, M., Othman, I., Mkic, M. and Al-Ashmori, Y.Y. (2020), "Rate of Occurrence of Fatal Accidents in Malaysian Construction Industry after BIM Implementation", International Journal of Engineering and Management Research, Vol. 2, 49-76.

Safetyline Institute (2005), Occupational Health and Safety Practitioner: Hazard, Energy and Damage, Worksafe, Western Australia.

Shah, M.N., Salleh, N., Nawi, M.N.M. (2016), Impact of serious game towards foreign worker in safety induction course in Malaysian construction industry. Rev. Tec. Ing. Univ. Zulia. 39(9), pp.1-8.

Shamsuddin, K. A., Ani, M. N. C., Ismail, A. K. and Ibrahim, M. R. (2015) Investigation the Safety, Health and Environment (SHE) Protection in Construction Area, International Research Journal of Engineering and Technology, Vol. 2, No. 6, pp.624-636.

SOCSO (2000), Annual Report for 2000, Social Security Organization, Kuala Lumpur, Malaysia SOCSO (2009), Annual Report for 2009, Social Security Organization, Kuala Lumpur, Malaysia.

SOCSO (2019), Annual Report for 2009, Social Security Organization, Kuala Lumpur, Malaysia.

Szymberski, R. (1997). “Construction Project Safety Planning”, TAPPI Journal, Vol. 80, pp.69-74.

Toole, T. M., \& Gambatese, J. (2008). The trajectories of Prevention through Design in construction. Journal of Safety Research, Vol. 39 No. 2, pp.225-230. 
Toulmin, S. (2012), The Uses of Argument 2nd Edition, Cambridge University Press, Cambridge, United Kingdom, p.262.

Viner, D. (1991), Accident Analysis and Risk Control, Viner Pty Ltd., New Delhi, India.

Yearwood, J. L. and Stranieri, A. (2006), "The Generic/Actual Argument Model of Practical Reasoning", Decis. Support Syst., Vol. 41 No. 2, pp.358-379.

Zhang S., Sulankivi, K., Kiviniemi, M., Romo, I., Eastman, C. M. and Teizer, J. (2015), "BIM-based fall hazard identification and prevention in construction safety planning", Safety Science, Vol. 72, pp.31-45. 